\title{
Supply Chain Operational Performance and Its Influential Factors: Cross National Comparison between Japan and China
}

\author{
Jingjing Gong \\ Tomohiro Ogasawara \\ Sadami Suzuki \\ Tokyo Institute of Technology (Tokyo Tech), Tokyo, Japan
}

\begin{abstract}
This research paper is intended to investigate the supply chain operational performance and its potential factors that constitute an efficient supply chain operational performance in Japan and China. In order to perform this, the SCM Logistics Scorecard (LSC) has been utilized as a selfevaluation tool for participating companies. The LSC focuses on four decisive areas, namely, company strategy, planning and execution capability, logistics performance, and IT method and implementation. The number of participating companies was 554 from Japan and 236 from China. The scores in each assessment area were compared between the two countries. Subsequently, factor analysis has been conducted by using the result of LSC in order to identify the significant factors which established the operational performance of SCM in each country. The result of the factor analysis indicated that the structure in generating successful SCM in Japanese industry and the Chinese were considered similar in the aspect of SCM realization, SCM strategy and the utilization of IT along the chain. Finally, the correlation between extracted factors and financial bottom lines was conducted, which indicated that improving SCM performance brought positive impact on financial outcome, especially when IT utilization in cooperation with SCM organization strategy.
\end{abstract}

Keywords: SCM Logistics Scorecard (LSC), Supply chain performance measurement, Factor analysis.

\section{Introduction}

With the information technology development and globalization of corporate activities, individual business in the $21^{\text {st }}$ century, have no longer competed as a solely independent entity, but rather as a supply chain. Companies associated in the same network require efficient supply chain integration to cooperate together in order to optimize their overall performance and achieve maximum benefits as a whole. Therefore, Supply Chain Management (SCM) has been subsequently considered as a vital foundation for improving business competence. Moreover, numerous companies have started to appreciate that SCM could play a key role in building sustainable competitive advantage for their products in a highly competitive market.

Supply chain performance measurement was earlier noted as a significant element to improve efficiency of the entire supply chain. Meanwhile, suitable and 
accurate performance measures could be used to not only drive business improvement continuously but also set directions for future organizational strategies (Kuwaitti and Kay, 2000). As for the existing SCM performance measurement tools, most of them consist of simple Likert scale based on questionnaires (Li et al., 2006). Although the SCM Logistics Scorecard (LSC) has been developed also based upon the concept of 5-point Likert scale, the definition on level 1-5 of each assessment item was clearly defined in its own way. Furthermore, the LSC was found to be efficient to analyze the relationship between supply chain performance and its managerial performance (Arashida et al., 2008), investigate the correlation between institutional environment and supply chain operations (Yaibuathet et al., 2004), identify influential factors which determine the SCM operational performance and their impacts on financial bottom line indexes (Suzuki et al., 2009). Therefore, SCM Logistics Scorecard (LSC) could be considered practical for utilizing it as a data collection tool for this research.

From these regards, this research extends these previous researches on LSC by collecting much more data samples and explores a cross national comparison of SCM operational perfomance between two Asian countries, namely Japan and China.

The first research objective mainly focuses on analyzing and comparing supply chain operational performance level between Japan and China. In this cross national comparison, the impact of cultural differences between Japan and China on the SCM operational performance were also discussed from the cultural perspective, since organization culture and company sophistication played an important role in the development of supply chain management. Consequently, the second objective of this study attempts to verify that whether different countries produce different weights on approaches to SCM building. In order to derive these approaches, factor analysis was conducted on the LSC data of each country. Finally, the extracted factors were also used to examine whether these factors represented as drivers in leading SCM operational performance to improve the financial outcomes of the focal companies.

The rest of this paper is organized in the following order. The LSC is explained in the subsequent section together with the data collection process in Japan and China. Data analysis which includes comparative analysis in different countries, the comparison on performance structures and the correlation between the extracted factors and the financial bottom line indexes are outlined in the section three. The conclusions and future research approach are given at the final section of this paper.

\section{SCM Logistics Scorecard (LSC) and Data Collection}

\section{SCM Logistics Scorecard (LSC)}

SCM Logistics scorecard (LSC) has been developed since 2001 by Tokyo Institute of Technology (Tokyo Tech) in collaboration with Japan Institute of Logistics system (JILS). The scorecard was built after conducting surveys on various renowned SCM scorecards, such as Efficient Consumer Response (ECR), Standard ECR (ECCC, 1998), Quick Response (QR) (QRLC, 1996), SCOR model (SCC, 1996) and so on. These existing scorecards were investigated through those measurement items. The Hayashi's Quantification Method (Type III) classification was subsequently conducted to configure the position of each scorecard between two dimensions: the performanceperformance driver orientation and the managerial-technical orientation. As a result, 
none of the existing scorecards was considered to balance between these two dimensions. For this reason, the ultimate goal of LSC is to have a balance of these two dimensions together within a simple and versatile concept in order to get an easy database building process for benchmarking purposes.

Consequently, the LSC encompasses 22 assessment items based on four fundamental areas, which are 1) Corporate Strategy and Inter-Organization Alignment; 2) Planning and Execution Capability; 3) Logistics Performance and; 4) IT Methods and Implementation. Each assessment item is allocated into five-point scale from one to five. The detailed description of each level is also given indicating the 5th level as the best practice for each item. This method is different from the normal Likert-scale questionnaire, which, for example, gives statements and asks participants to judge themselves as strongly disagree (Level 1) to strongly agree (Level 5). With clearly provided information on each level, not only the respondents could identify themselves more precisely but also the bias among them could be reduced. The score of one integer and a half (for example 2.5) is also acceptable for managers who placed their companies between two levels. Despite the generality of this scorecard, individual companies could perform their self-assessment, and then compare their performance with competitors in the same industry cluster as well as across sectors. The result of this assessment could indicate the strengths and weaknesses of the existing working method from an SCM perspective (Suzuki et al., 2007, 2009). The detail of LSC is presented in the Appendix 1.

\section{Data Collection Process}

The LSC data collection has been carried out initially in Japan and then extended to China, Thailand, Finland and South Korea in order to expand LSC research scope to international comparisons. Accordingly, the LSC has been translated into other languages including English, Chinese, Thai, Finnish and Korean from its original version in Japanese.

The data collection process in Japan was launched in 2001 in cooperation with Tokyo Tech and JILS. Putting the most priority on data reliability, most data were obtained by interviewing high-level managers. The company evaluation through LSC was executed after the interview, which were conducted to ensure the identical understanding to the respondents, for example, the instructions of using LSC. A feedback report was then sent back to each respective company. This report contained the results of the company compared with others in the same group of industrial type including the rank among competitors. Thus, the provided incentive could maintain the reliability level of the achieved data. Then, the data collection has been extended to China from 2006 in cooperation with Tsinghua University, Xi'an Jiaotong University and Shanghai Jiaotong University. Most of the collection processes in China were followed those in Japan as well as targeted respondents. Meanwhile, Chinese data collection has been carried out without providing company feedback report.

Although at the time of writing, 1037 data have been collected from Japanese companies since 2001, because the LSC data collection has been launched in China since 2006, and in order to make the comparison analysis more objectively, only 554 Japanese data were used in this research, which have been obtained since 2006 which were consistent with Chinese data collection process. As for the Chinese 
companies, 236 valid data were successfully obtained. The category of LSC data both from Japan and China are shown in Table 1.

\section{Data Analysis}

\section{Primary comparison between Japan and China}

The purpose of this section is to accomplish the first objective of this research. Attempt has been made to verify that SCM performance level between Japan and China is different, and it may be influenced by different cultures. As a result of the data collection process, the data attribute and the distribution of the total score (110) between Japanese and Chinese companies are shown in Table 2 and Figure 1.

In order to ensure the reliability of LSC data which was used in this paper, the Cronbach's coefficient alpha was calculated during the data collection process. The results were shown in terms of Cronbach's coefficient alpha at 0.965 for 22 assessment items from Japanese data and 0.957 from Chinese data. These results indicated that high reliability of LSC was ensured. As the data attribute revealed, the average total score between Japanese and Chinese companies were different. Also, the standard

Table 1. Category of participating companies.

\begin{tabular}{|c|c|c|}
\hline & Japan & China \\
\hline Food & 70 & 9 \\
\hline Electronics & 71 & 85 \\
\hline Automotive & 99 & 16 \\
\hline Chemistry & 93 & 39 \\
\hline Fiber & 8 & 4 \\
\hline Pharmaceutical & 17 & 1 \\
\hline Others & 196 & 82 \\
\hline Total & 554 & 236 \\
\hline
\end{tabular}

Table 2. Data attribute of total score between Japanese and Chinese companies.

\begin{tabular}{|c|c|c|}
\hline & Japan & China \\
\hline Number of data & 554 & 236 \\
\hline Mean & 62.53 & 65.94 \\
\hline Std. Dev & 15.01 & 18.94 \\
\hline Variance & 225.29 & 358.86 \\
\hline Median & 61 & 67 \\
\hline Mode & 54 & 83 \\
\hline Range & 91 & 86 \\
\hline Maximum & 105 & 110 \\
\hline Minimum & 14 & 24 \\
\hline
\end{tabular}


deviation, variance and range of Chinese data were larger than Japanese, which meant that Chinese data showed higher degree of variation.

From the distribution chart of total score between Japan and China, it could be observed that the Japanese data presents a normal distribution, while the Chinese data is shown as a bimodal distribution. This polarization of Chinese data distribution may be caused by regional and cultural disparity. The average total score of these two countries were found different at significant level where the Chinese companies produced high scores than those from Japanese companies.

The average score and standard deviation of four fundamental areas were calculated and represented in Figure 2 and Table 3. $T$ test is respectively conducted on total score with each average area score to identify whether those scores are influenced by country difference. The outcome of t-test is also presented in Table 2. Findings from t-test demonstrate that $t$-values of total score and all average area scores, except for area 4 , are less than 0.05 , confirming that those scores are statistically different. Chinese

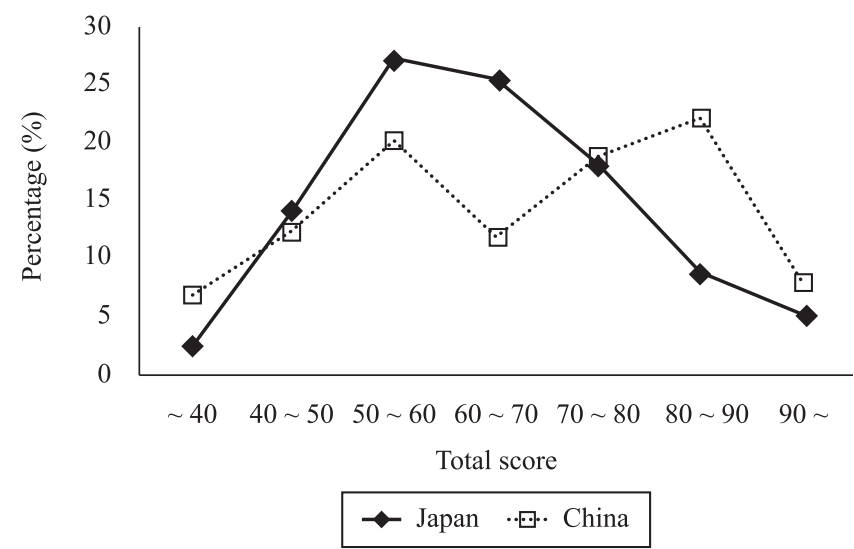

Figure 1. Distribution chart of LSC total score between Japan and China.

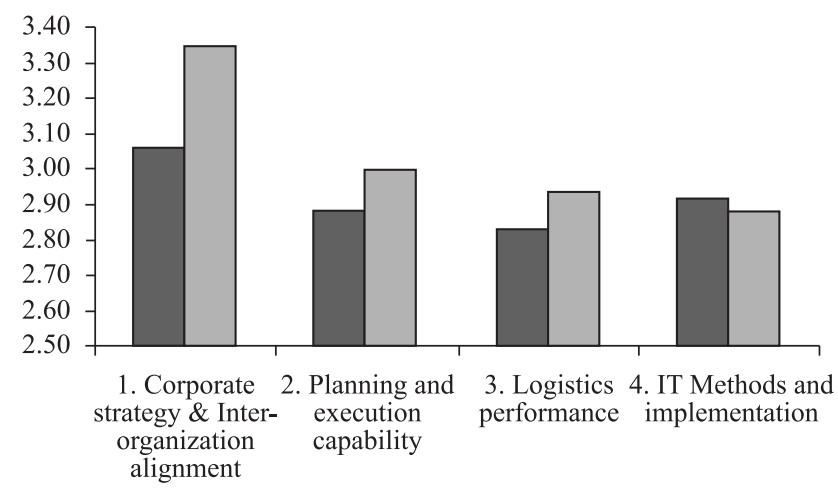

$\square$ Japan (554) $\square$ China (326)

Figure 2. Average scores of four areas between Japanese and Chinese companies. 
companies occupied higher scores than Japanese ones, especially in area (1) Corporate Strategy and Inter-Organization Alignment, taking up the biggest difference which was noticeable at a fairly high significant level. On the other hand, the area (4) IT Methods and Implementation was dominated by the Japanese companies but not at significant level. The comparative result of each assessment item between Japanese and Chinese companies was also pointed out to recognize the strengths and weaknesses including the variation of those 22 items. This result is displayed in Figure 3 as a radar chart so as to make the data more understandable.

The highest competence items for Japanese industry were revealed in the strategies for optimizing logistics system resources based on design for logistics (item 2-1), delivery performance and quality (item 3-4) and give great attention to environmental activities (item 3-6). Japanese companies also outperformed in using

Table 3. Average scores of four areas between Japanese and Chinese companies.

\begin{tabular}{|c|c|c|c|c|c|}
\hline \multirow{2}{*}{$\begin{array}{c}\text { Assessment } \\
\text { Item }\end{array}$} & \multicolumn{2}{|c|}{ Japan (554) } & \multicolumn{2}{c|}{ China(236) } & \multirow{2}{*}{$t$ test } \\
\cline { 2 - 5 } & Average & SD & Average & SD & \\
\hline 1. Corporate strategy and inter-organization alignment & 3.06 & 0.71 & 3.35 & 0.90 & $-4.95 * *$ \\
\hline 2. Planning and execution capability & 2.88 & 0.71 & 3.00 & 0.94 & $-1.88^{*}$ \\
\hline 3. Logistics performance & 2.83 & 0.69 & 2.93 & 0.92 & $-1.78^{*}$ \\
\hline 4. IT methods and implementation & 2.91 & 0.75 & 2.88 & 1.02 & 0.51 \\
\hline Average total LSC score & 2.91 & 0.64 & 3.04 & 0.86 & $-2.32 *$ \\
\hline
\end{tabular}

*: $5 \%$ significant; $* *: 1 \%$ significant

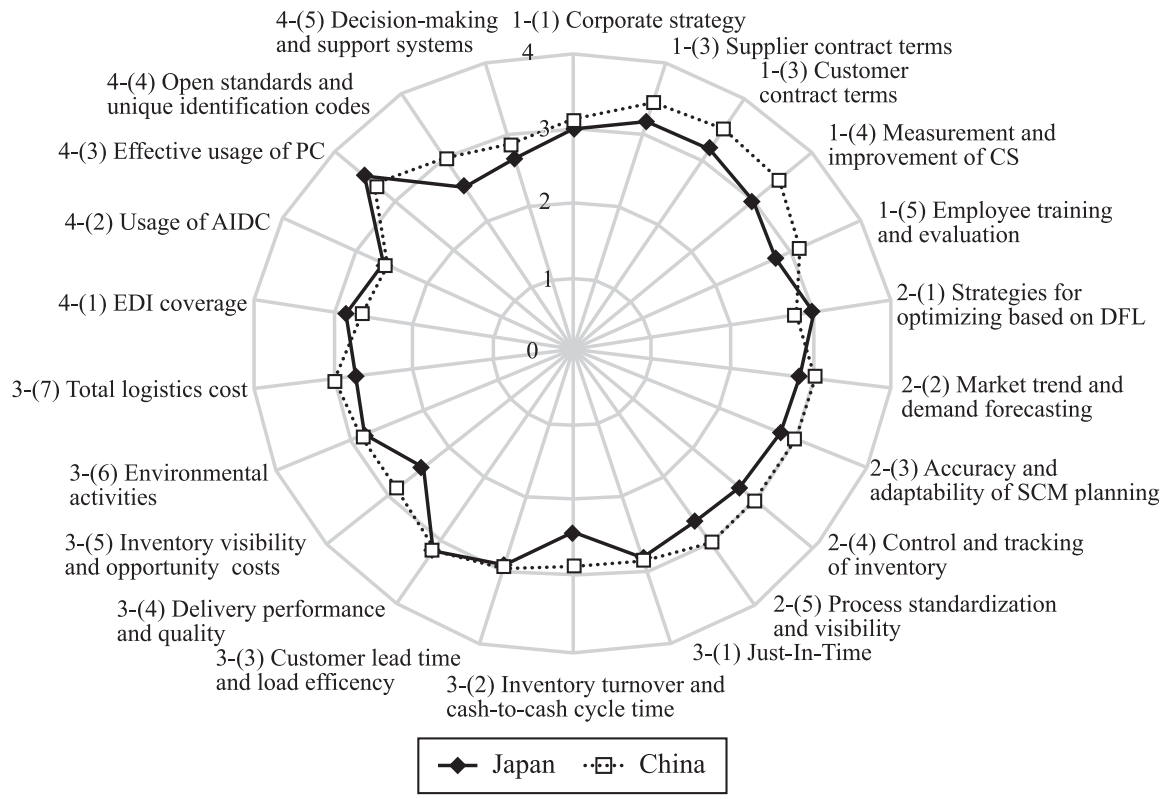

Figure 3. Radar chart of the LSC result between Japan and China. 
IT evolution such as introducing bar coding systems to synchronize the material and information flow, use electronic data interchange systems in the supply chains (item 4-1,4-2) and take effective usage of computers in operations and decision-making issues (item 4-3). On the other hand, Chinese companies focused on the capability of supply chain management, especially on clarifying contracts and sharing information with customers and suppliers, while much attention has also been paid on improving employee' abilities to response to customer satisfaction. This conclusion was derived from the superior score in areas (1), (2) and (3).

The preliminary comparison shows that the Chinese industry was found to occupy the higher scores with the higher degree of variation. Findings after the $t$ test confirmed that the supply chain operational performance level was statistically different between Japan and China. The result of raw score comparison between Japan and China could be considered by the following two aspects. On one hand, around $42 \%$ of Chinese participants were foreign owned enterprises, which could have obtained advanced knowledge, manufacturing standards and technologies, marketing and management systems from their mother companies in the US, Japan, Germany and so on. Those subsidiary companies must improve their competitive advantages by increasing the product quality, reducing inventory cost as well as leveling up the customer responsiveness instead of decreasing labor cost. Otherwise, the mother companies may relocate their manufacturing base to other countries which may influence the whole country's economy. Moreover, the domestic firms which confronted a high competition with foreign companies at home and abroad, must improve their competitiveness, or they would be eliminated.

On the other hand, the comparison results also can be explained by the different cultures in the two countries. According to Takada (2003), Japanese people tend to be self-critical or evaluate themselves negatively when they are under a competition-free situation and feel affective bonds to others. Since the Japanese respondents were told that the LSC evaluations were a contribution for academic research and their results would be kept secret, the modestly rating may be tracked down among Japanese participants. On the other side, some studies indicate that, with the economic development, Chinese people become more and more individualistic, and they have a tendency to evaluate themselves rather leniency (Xie et al., 2006), therefore, it could be speculated that Chinese people may rate themselves higher than their actual performance.

\section{Comparative Analysis on Performance Structure}

In this section, the factor analysis was carried out in order to verify the hypothesis that each assessment item has relationship among each other. In addition, this analysis could extract the influential factors, which determine the operational performance of SCM, and determine whether Japan and China have distinctive managerial approach or orientation to SCM. Factor analysis is a statistical data reduction technique used to explain variability among observed random variables in terms of fewer unobserved variables, known as factors. The factor analysis was conducted separately with the data from each country, 554 samples from Japan and 236 from China. The initial solution was performed by the principal axis factoring with the constraint of eigen-value more than one. The result indicated that three factors were extracted from Japanese data with the cumulative 
contributions rate at $47.93 \%$, whereas, two factors were obtained from Chinese data at the cumulative contributions rate of $54.47 \%$. In order to simplify the factor comparison between these two countries, the number of Chinese extracted factors was limited to three during the principal axis factoring analysis. Therefore, three factors were obtained from Chinese data with the cumulative contribution rate at $57.34 \%$. Varimax rotation was used during the process of factor analysis in order to remain the independent relations among the extracted factors. The factor matrix is shown in Table 4, the items with factor loading more than 0.4 as well as the highest loading for each item are highlighted in dark.

Table 4. Rotated factor matrix of 554 Japanese and 236 Chinese samples.

\begin{tabular}{|c|c|c|c|c|c|c|}
\hline \multirow{2}{*}{ Assessment Item } & \multicolumn{3}{|c|}{ Factor (Japan) } & \multicolumn{3}{|c|}{ Factor (China) } \\
\hline & 1 & 2 & 3 & 1 & 2 & 3 \\
\hline $\begin{array}{l}\text { 1-(1)Corporate strategy regarding logistics and its } \\
\text { importance }\end{array}$ & .354 & .593 & .235 & .379 & .270 & .582 \\
\hline $\begin{array}{l}\text { 1-(2)Definition of supplier contract terms \& degree of info } \\
\text { sharing }\end{array}$ & .435 & .555 & .249 & .249 & .227 & .700 \\
\hline $\begin{array}{l}\text { 1-(3)Definition of customer contract terms \& degree of info } \\
\text { sharing }\end{array}$ & .305 & .591 & .211 & .159 & .212 & .660 \\
\hline 1-(4)System for measurement and improvement of CS & .268 & .530 & .170 & .415 & .210 & .602 \\
\hline 1-(5)System for employee training and evaluation & .305 & .615 & .218 & .395 & .304 & .481 \\
\hline $\begin{array}{l}\text { 2-(1)Strategies for optimizing logistics system resources } \\
\text { based on DFL }\end{array}$ & .501 & .388 & .358 & .399 & .505 & .374 \\
\hline $\begin{array}{l}\text { 2-(2) Understanding of market trends \& accuracy of demand } \\
\text { forecasting }\end{array}$ & .370 & .272 & .222 & .484 & .350 & .423 \\
\hline 2-(3)Accuracy and adaptability of SCM planning & .607 & .303 & .208 & .516 & .321 & .430 \\
\hline $\begin{array}{l}\text { 2-(4)Control and tracking of inventory: accuracy and } \\
\text { visibility }\end{array}$ & .669 & .211 & .242 & .468 & .344 & .515 \\
\hline 2-(5)Process standardization and visibility & .572 & .436 & .304 & .546 & .401 & .457 \\
\hline 3-(1)Just-In-Time & .586 & .336 & .398 & .588 & .427 & .297 \\
\hline 3-(2)Inventory turnover \& cash-to-cash cycle time & .515 & .318 & .273 & .672 & .379 & .240 \\
\hline 3-(3)Customer lead time and load efficiency & .579 & .217 & .293 & .590 & .280 & .252 \\
\hline 3-(4)Delivery performance and quality & .484 & .277 & .315 & .720 & .227 & .305 \\
\hline 3-(5)Supply chain inventory visibility \& opportunity costs & .546 & .374 & .275 & .554 & .431 & .302 \\
\hline 3-(6)Environmental activities & .117 & .487 & .307 & .520 & .295 & .280 \\
\hline 3-(7)Total logistics cost & .440 & .366 & .276 & .594 & .446 & .323 \\
\hline 4-(1)Electronic Data Interchange (EDI) coverage & .360 & .150 & .627 & .283 & .667 & .199 \\
\hline 4-(2)Usage of bar coding/AIDC & .291 & .278 & .579 & .327 & .647 & .137 \\
\hline $\begin{array}{l}\text { 4-(3)Effective usage of computers in operations and } \\
\text { decision-making }\end{array}$ & .227 & .246 & .433 & .238 & .600 & .388 \\
\hline 4-(4)Open standards and unique identification codes & .270 & .411 & .520 & .331 & .626 & .395 \\
\hline $\begin{array}{l}\text { 4-(5)Decision-making systems and support to supply chain } \\
\text { partners }\end{array}$ & .423 & .380 & .488 & .339 & .565 & .336 \\
\hline
\end{tabular}


From the Japanese findings, factor one showed strong relationship with all items in area (2) and area (3) except the item 3-(6). Since these items may account for the agility and flexibility to market changes including the ability to respond to customer requirements, this factor was named as "Responsiveness". Meanwhile, since factor two had high correlation with all the items from area (1) and environmental activities, which are related to the organizational issues in order to build up the efficient supply chain, it was entitled as "SCM Organization Ability". Factor three was related to all items in area (4), it was, therefore, named as "IT Utilization Ability". Since the raw score of each item in LSC can be considered as a result of the capability of these factors, these three factors were identified as the measurement indices for SCM operational performance of Japanese sector.

With respect to the results from Chinese companies, three factors were defined as follows. The first factor was found to have high relationship with most items from area (2) and all items from area (3), thus, it was also called "Responsiveness". Subsequently, the second factor was examined to identify the related items, which were all from area (4) with some contents of 2-(1) that concerned with the strategies for optimizing logistics system resources based on design for logistics. Therefore, the specified name was "IT utilization ability" too. The uncovered final factor had strong correlation with corporate strategy and Inter-organization alignment, in this case, "SCM Organization Ability" was designated for this factor. Consequently, three factors were extracted from Chinese data to point out the structure of generating efficient supply chain for Chinese industry.

The result of the factor analysis revealed that the factors which identify their SCM competencies were considered similar between Japan and China. From the pattern matrix, it was worthwhile to note that both Japanese and Chinese respondents considered the SCM organization issues and technical issues independently. However, the results indicated a slight contradiction to previous research findings, that is, the analysis results both from Finland and Thailand revealed that supply chain organization strategy and IT utilization were considered together as one factor extracted from factor analysis (Yaibuathet et al., 2007). The decisive difference could be explained by the fact that Japanese and Chinese people are all identified to the oriental Confucian culture and both of them have a high long-term orientation (Hofstede, 1994). They believe that the building of long-term collaboration with suppliers is very important, and the IT usage just plays a separated role as an enabler to achieve higher SCM performance. While, both Finland and Thailand seems to believe that effective IT utilization do assist in delivering right strategy about SCM throughout the organization as well as achieving a high degree of information sharing among business partners.

\section{Correlation Analysis Between SCM Operational Performance and Financial Indexes}

In this section, regression analysis was conducted to analyze the relationship between three factors which were extracted from LSC and the financial bottom line indexes in order to verify that whether these factors represent as drivers in leading successful SCM operational performance to the financial outcome. During this process of regression analysis, the independent variables were companies' scores for the extracted three factors and the dependent variables were companies' indexes of 
financial outcome. According to previous research (Yaibuathet et al., 2007), some time-lag considerations which reflect SCM operational performance to the managerial effectiveness have to be taken into account. Theoretically, it could be considered that efficient SCM operational performance could lead to better inventory management, and then, inventory reduction could lead to enhance better cash flow and ROA in a time-lag process. Thus, the following time-lagged data of the financial bottom line indexes were used, that is, the inventory turnover period in the same year when the LSC data were collected, one year later for cash flow and two years later for ROA.

Since the number of financial data from China were only 24 , it was too limited to be analyzed in this section. Therefore, only the Japanese data were utilized to explore the correlation between each factor and the corresponding company's financial bottom line indexes such as ROA, Cash Flow (CF) and the Inventory Turnover Period (ITP) which were obtained from Nikkei Economic Electronic Databank System CD-ROM (NEEDS).

The result of correlation analysis is shown in Table 5. Focusing on independent effect of each factor, it can be seen that, Responsiveness just had a significant impact on inventory turnover period, which indicated that improvement in the ability to respond to market could reduce the inventory turnover period. SCM Organization Ability took a significant positive correlation with ROA and CF, while IT Utilization Ability was found to have little relation with these three selected financial indexes. Since, an improvement in the ability of responsiveness seems to reduce inventory turnover period, this operational performance factor just has a short-term effect on financial performance. Meanwhile, enhancing the SCM organizational ability could produce significant financial outcomes in a long-term effect. The implementation of IT is also a vital factor which can influence the operational performance in supply chain. However, improving IT capability alone can't be a distinctive factor directly related to financial performance without a proper organization management (Shin, 2001). As well as for the suggestion of the well-known "IT Paradox", it is difficult to obtain a directly positive effect from IT investment to operational outcomes. Therefore, as shown in Table 5, the IT utilization in cooperation with SCM organization strategy was analyzed, the result illustrated that synergetic effect of organization ability and IT utilization could yield better financial outcomes than the merely extension of IT usage or organization ability separately in supply chain.

Table 5. Correlation between SCM operational performance and financial indexes (Japan).

\begin{tabular}{|c|c|c|c|}
\hline $\mathrm{N}=229$ & ROA & CF & ITP \\
\hline \multirow{2}{*}{ Responsiveness } & -0.004 & 0.014 & $-0.144^{*}$ \\
& $(0.473)$ & $(0.416)$ & $(0.015)$ \\
\hline \multirow{2}{*}{ SCM organization ability } & $0.114^{*}$ & $0.125^{*}$ & 0.089 \\
& $(0.042)$ & $(0.029)$ & $(0.091)$ \\
\hline IT utilization ability & 0.108 & 0.060 & -0.075 \\
& $(0.051)$ & $(0.183)$ & $(0.130)$ \\
\hline \multirow{2}{*}{ Org. $\times$ IT } & $0.140^{*}$ & $0.128^{*}$ & 0.003 \\
& $(0.017)$ & $(0.026)$ & $(0.484)$ \\
\hline
\end{tabular}

The result in parentheses is p-value. *: $5 \%$ significant 


\section{Conclusions and Future Research}

In this research, the SCM Logistics Scorecard (LSC) was utilized as an evaluating instrument to investigate the supply chain operational performance and its potential factors which constitute an efficient SCM in Japan and China, respectively. As well, the correlation between SCM operational performance and financial indexes were analyzed based on Japanese data. The findings and implications were concluded as follows:

First, the preliminary comparison between Japanese and Chinese participants' data indicated that performance level scores from the two observed countries were statistically different, and Chinese scores were higher than Japanese. In addition to the reason that foreign owned enterprises seemed to influence the overall performance of Chinese industry, this unexpected result could be explained by the different cultures between the two countries. As for China, the average score of area (1) was unexpectedly higher than those from Japan, which could be explained by China's unique cultureGuanxi. Guanxi operated as a governance mechanism which brings direct effects on market performance and indirect effects through channel capability and responsive capability in the transitional economy of China (Flora et al., 2008). However, building up Guanxi would take a lot of time and costs, and managers should also be aware of Guanxi's risks including reciprocal obligations, corruption, ethical issues and so on. Moreover, according to the Hofstede's cultural dimensions, the Chinese culture is identified in the low uncertainty avoidance (UAI) dimension (Hofstede, 1984), that is, Chinese people have a tendency to evaluate themselves rather leniency. As a contrast, the Japanese culture is attributed to have a high uncertainty avoidance (UAI) position. This means that the people who are in the high UAI country tend to show more rigor, anxiety and stress, and they are very strict to themselves, consequently, they evaluate themselves rather modestly or strictly. Also, according to Enkawa's research (2010), the SCM performance is lower as UAI is higher.

Second, the results of factor analysis indicated that the potential factors which impact Japanese supply chain performance structures were similar to the Chinese except for the factor arrangement, but different from previous research. The most significant difference was that the IT usage was not identified as a unique factor from Thai and Finnish data sets, but as an independent factor in Japan and China. The result may be explained by that, both Japanese and Chinese think that long-term collaboration with business partners is very important, and the IT usage is just an enabler to achieve better SCM performance. Meanwhile, both Finland and Thailand seem to believe that effective IT utilization cooperating with strategy throughout the organization could achieve a high degree of SCM operational performance. In addition, the reason why Japanese and Chinese companies build a similar structure of SCM may be explained by that, after China's reform and open policy, China have been adapting lots of structures from Japan, especially, the business management thinking, method and economic development model, which are deeply influenced by Japan's management thought. Thus, the way of building SCM is similar between Japan and China.

Third, based on these results, the correlation analysis was conducted between extracted potential factors and financial bottom line indexes from Japanese companies, in order to verify that whether these factors represent drivers in leading successful SCM operational performance to improve the financial outcome. The findings show that Responsiveness has a significant impact on inventory turnover period, and SCM Organization Ability takes a significant positive correlation with ROA and CF, but IT 
Utilization Ability has weak relation with financial indexes. However, when considering IT utilization in cooperation with SCM organization strategy, a stronger relationship with financial outcomes could be appeared than when they are considered separately. It is implied that organization strategy is a vital element to enhance IT usage in a company and later bring growth on financial performance. Thus, it is a weakness both for Japan and China, the SCM Organization Stragety and IT Utilization are independent factors to their SCM building.

Since this paper only examines the performance structure between Japan and China in national level, the future research will draw attention to investigate the interactions among different industries as well as their ownership status. In addition, the correlation analysis was conducted between influential factors and financial indexes just based on Japanese data. In order to verify the relationship more clearly, much more financial data are expected to be obtained from developed and developing countries in the future.

Finally, the scope of this research is expected to be extended to collaborate with national organizations for systematic data collection in a larger scale in order to create a reliable database in future. It is also further expected that the directions provided in this research would be utilized as a prototype for investigating and enhancing supply chain operational performance in other newly industrialized developing countries.

\section{References}

Arashida, K.; Enkawa,T.; Hamasaki, A. and Suzuki,S. (2004) Developing the SCM logistics scorecard and analysing its relation to the managerial performance. Journal of Japan Industrial Management Association, Vol. 55, No.2, pp.95-103.

Electronic Commerce Council of Canada - ECCC. (1998) Efficient Consumer Response (ECR). Scorecard: ECCC.

Enkawa, T. (2010) A Cultural Perspective on Japanese Strengths and Weaknesses in Operation Management. Journal of Japan Industrial Management Association, Vol. 61, No. 3, pp.131-138.

Flora, F.G.; Hung, K. and David, K.T. (2008) When does guanxi matter ? Issues of capitalization and its dark sides. Journal of Marketing, Vol. 72, pp.12-28. http://dx.doi. org/10.1509/jmkg.72.4.12

Hofstede, G. (1984) Cultural Dimensions In Management And Planning. Asia Pacific Journal of Management, Vol. 1, No. 2, pp.81-99. http://dx.doi.org/10.1007/BF01733682

Hofstede, G. (1994) Management Scientists Are Hunman. Management Science, Vol. 40, No. 22, pp.4-12. http://dx.doi.org/10.1287/mnsc.40.1.4

Kuwaitti, M.E. and Kay, J.M. (2000) The role of performance measurement in business process re-engineering. International Journal of Operations and Production Management, Vol. 20, No.12, pp.1411-1426. http://dx.doi.org/10.1108/01443570010353086

Li,S.; Ragu-Nathan,B.; Ragu-Nathan,T.S. and Rao,S.S (2006) The impact of supply chain management practices on competitive advantage and organizational performance. OMEGA: The international Journal of Management Science, Vol. 34, pp.107-124.

Quick Response Leadership Committee - QRLC. (1996) QRLC Measurements for Excellent. American Apparel Manufactures Association (AAMA).

Shin, N. (2001) The impact of information technology on financial performance: the importance of strategic choice. European Journal of Information Science, Vol. 10, No.4, pp.227-236. http://dx.doi.org/10.1057/palgrave.ejis.3000409

Supply Chain Council - SCC. (1996) Supply Chain Operation Reference-Model. SCOR version 10.0. Supply Chain Council, Inc. 
Suzuki, S.; Ohno, A. and Enkawa, T. (2007) Quantifying Inter-organizational Recognition Gaps which Impede SCM Efficiency. Journal of Japan Logistics Society, Vol. 7, No. 2, pp.11-19.

Suzuki, S.; Kitamura, S. and Enkawa, T. (2009) The Influence of Market Uncertainty on SCM Competencies and Managerial Performance. Journal of Japan Industrial Management Association, Vol. 60, No. 2, pp. 69-76.

Takada, T (2003) Self-enhancement and self-criticism in Japanese culture. Journal of Cross-cultural Psychology, Vol. 34, No. 5, pp.542-551. http://dx.doi.org/10.1177/0022022103256477

Xie, J.L.; Chen, Z. and Roy, J.P. (2006) Cultural and personality determinants of leniency in self-rating among Chinese people. Management and Organization Review, Vol. 2, No. 2, pp.181-207. http://dx.doi.org/10.1111/j.1740-8784.2006.00043.x

Yaibuathet, K.; Enkawa, T. and Yoshika, T. (2007) Impact of Information Technology and SCM Organizational Strategy on Corporate Financial Performance and Its Cross National Comparison. International Journal of Information Systems for Logistics and Management, Vol. 3, No.1, pp.13-24

Yaibuathet, K.; Enkawa, T. and Suzuki, S. (2007) Supply Chain Operational Performance and Its Influential Factors: Cross National Analysis. Journal of Japan Industrial Management Association, Vol. 57, No.6, pp.473-482.

Yaibuathet, K.; Enkawa, T. and Suzuki, S. (2008) Influences of Institutional Environment Toward the Development of Supply Chain Management. International Journal of Production Economics, Vol. 115, No.2, pp.262-271. http://dx.doi.org/10.1016/j.ijpe.2008.02.018

\section{Biography}

Jingjing Gong received her Master degree in Jilin University, China (2009). She is a research student in the Department of Industrial Engineering and Management, Tokyo Institute of Technology, Japan from 2010. She will continue to conduct researches at the doctorial course in the same department from this October. Her research interest is in Operations Management, mainly concerned with Supply Chain Management, New Product Development.

Contact: hamigua89@gmail.com

Tomohiro Ogasawara received his B.Eng. in the Department of Industrial Engineering and Management, Tokyo Institute of Technology, Japan (2010). He is a master course student there and conducts research to obtain his Master degree. His research interest is in Operations Management, mainly concerned with Supply Chain Management, Financial Engineering.

Contact: ogasawara.t.aa@m.titech.ac.jp

Sadami Suzuki is an Associate Professor in the Department of Industrial Engineering and Management, Tokyo Institute of Technology, Japan. He received his B.Eng., M.Eng and D.Eng. from Tokyo Institute of Technology in 1998, 2000, 2007 respectively. His research are focuses in Production and Operations Management, mainly concerned with Supply Chain Management, Logistics and Theory of Constraints.

Contact: suzuki.s.ag@m.titech.ac.jp

\section{Article Info:}

Received: September, 2011

Accepted: December, 2011 


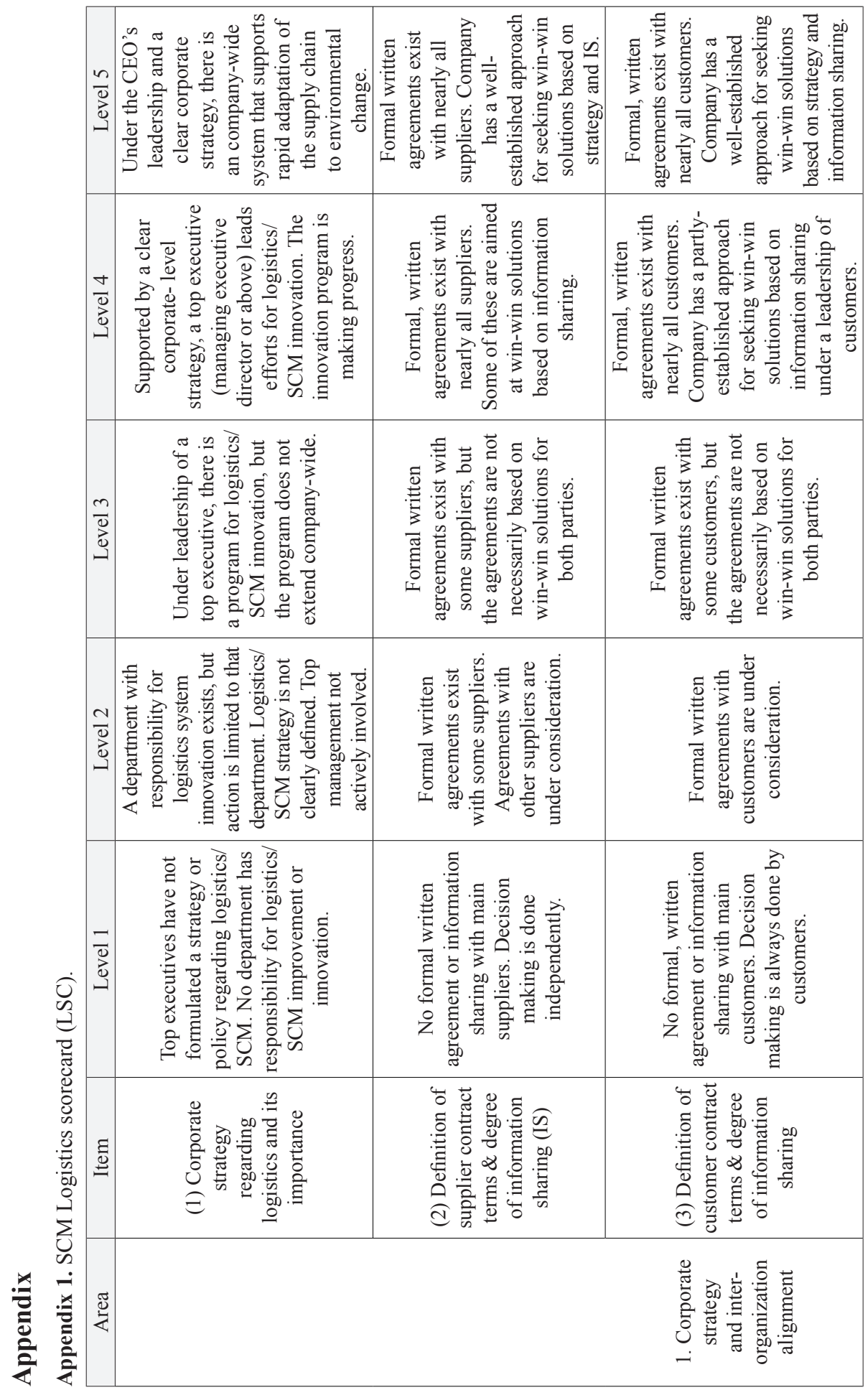




\begin{tabular}{|c|c|c|c|}
\hline & 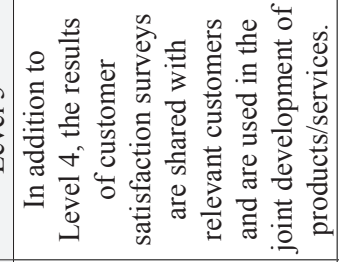 & 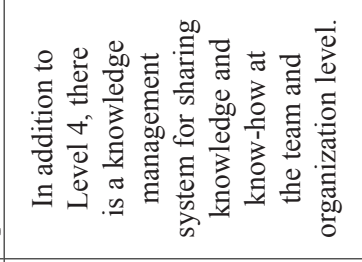 & 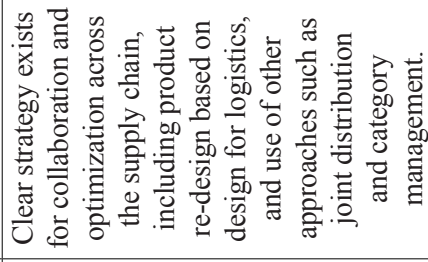 \\
\hline & 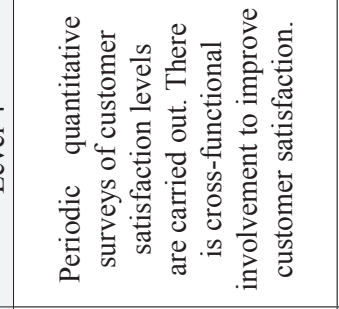 & 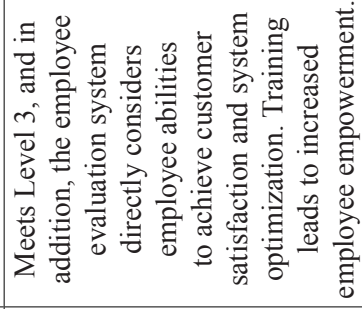 & 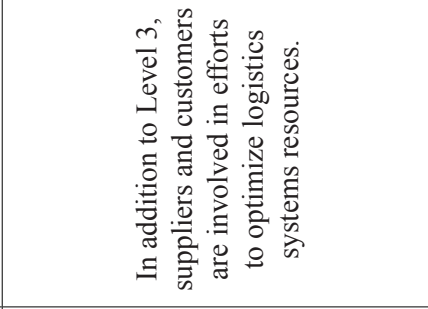 \\
\hline & 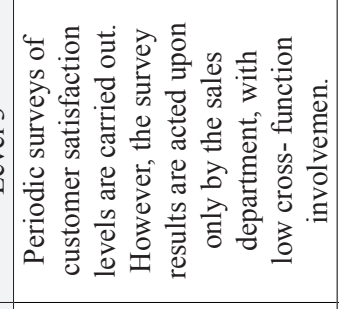 & 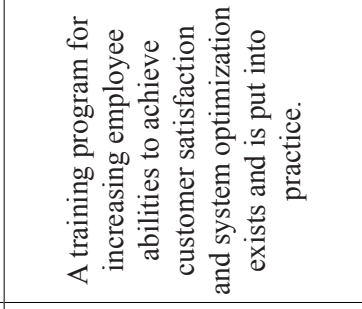 & 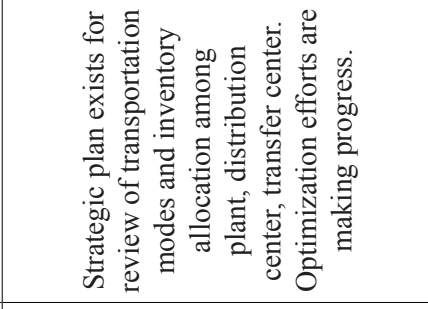 \\
\hline & 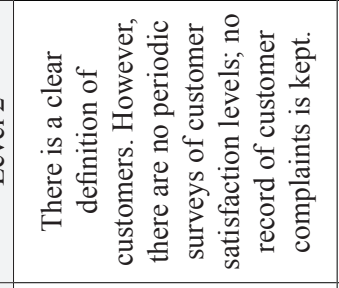 & 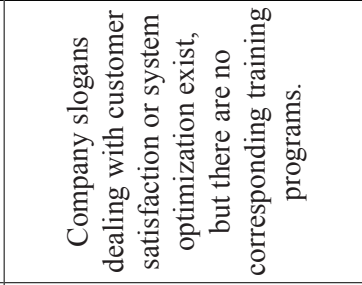 & 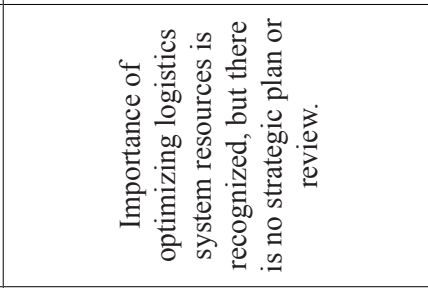 \\
\hline & 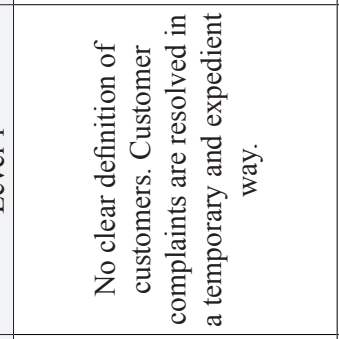 & 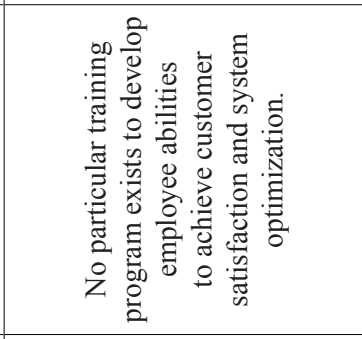 & 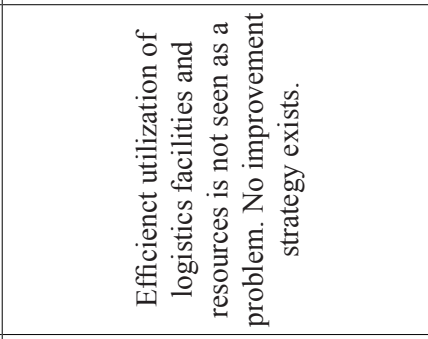 \\
\hline & 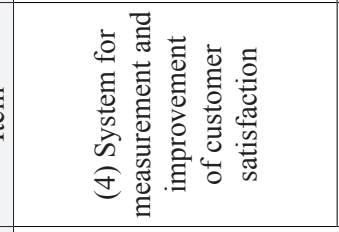 & 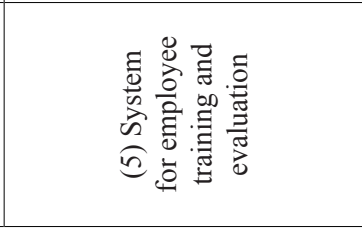 & 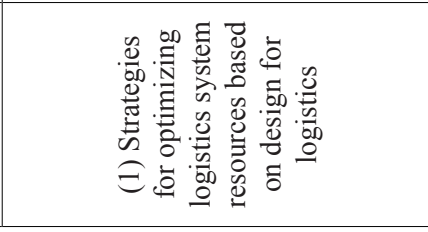 \\
\hline & & & \\
\hline
\end{tabular}




\begin{tabular}{|c|c|c|c|}
\hline & 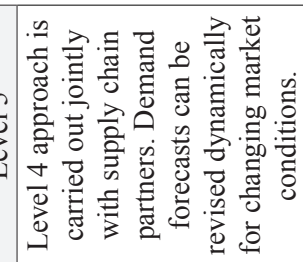 & 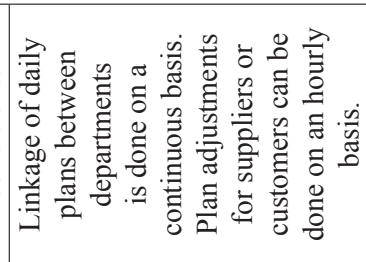 & 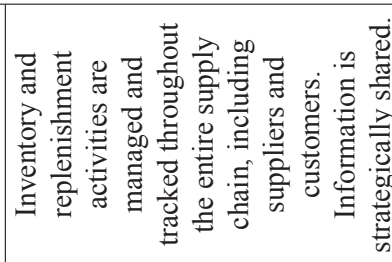 \\
\hline & 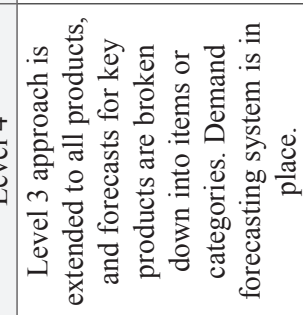 & 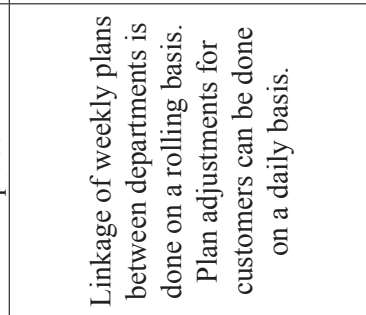 & 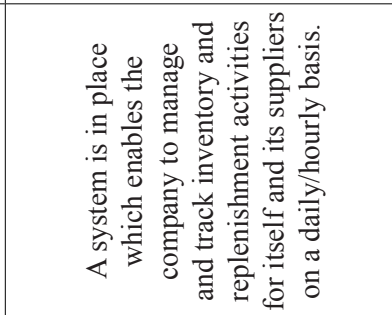 \\
\hline & 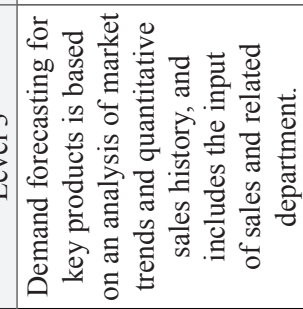 & 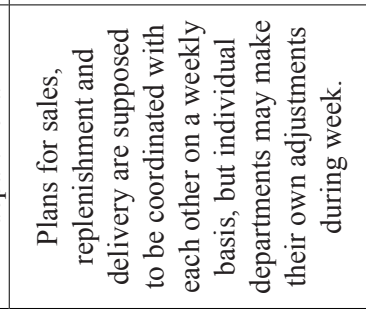 & 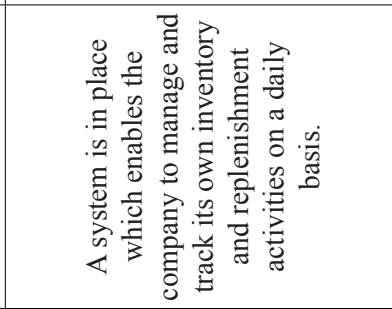 \\
\hline & 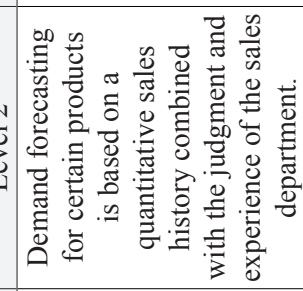 & 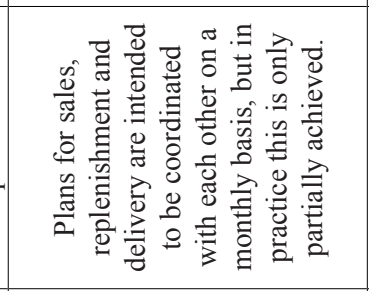 & 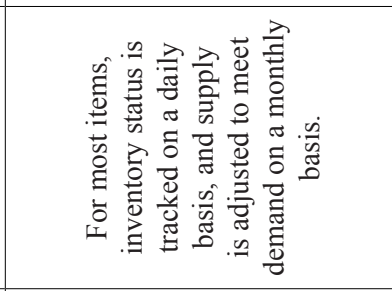 \\
\hline & 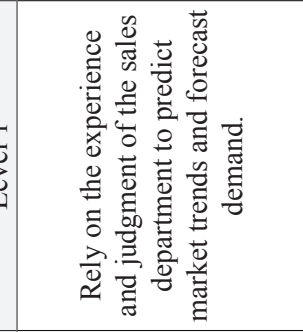 & 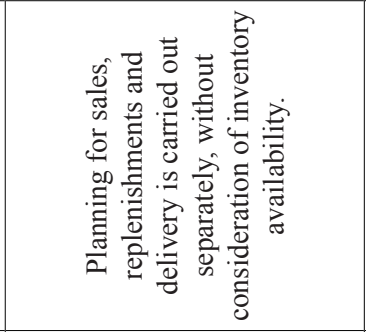 & 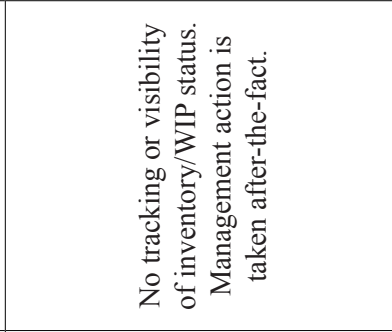 \\
\hline & 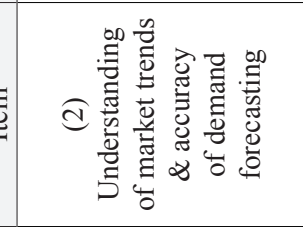 & 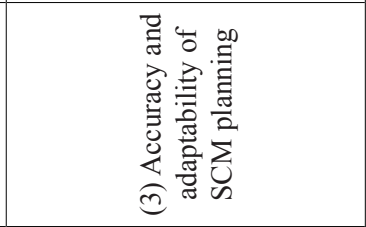 & 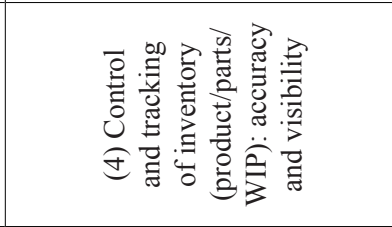 \\
\hline & & 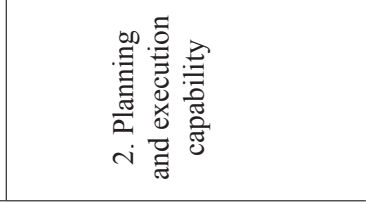 & \\
\hline
\end{tabular}




\begin{tabular}{|c|c|c|c|}
\hline & 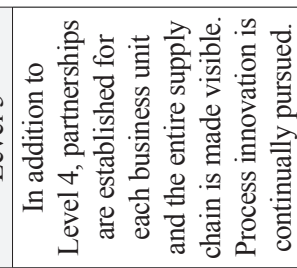 & 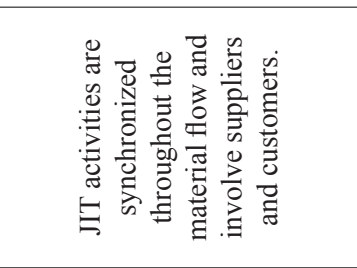 & 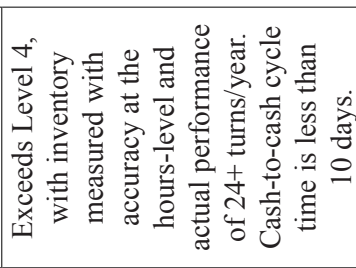 \\
\hline & 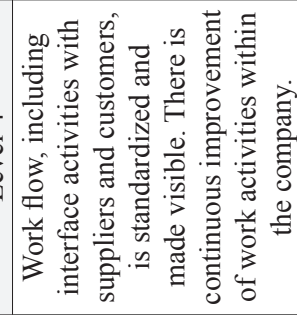 & 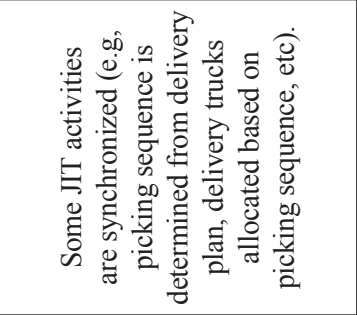 & 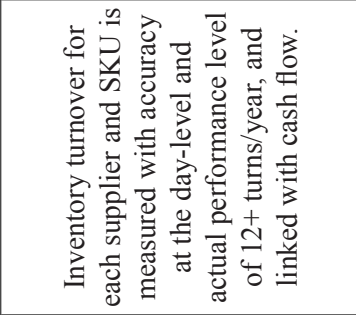 \\
\hline & 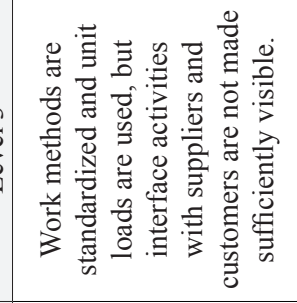 & 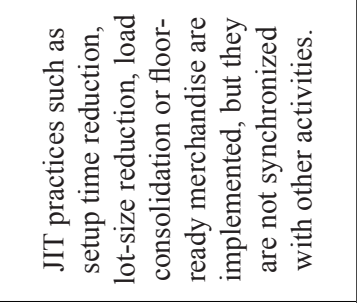 & 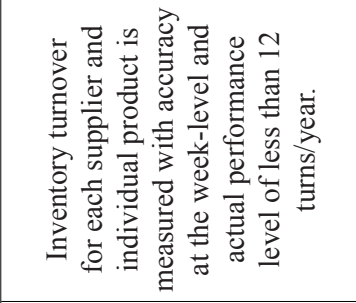 \\
\hline & 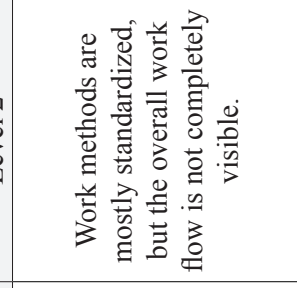 & 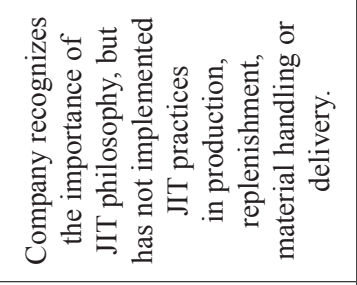 & 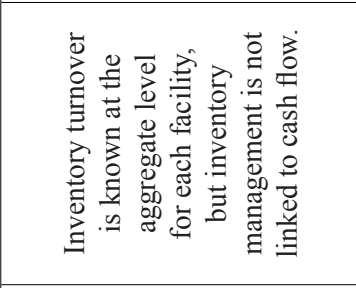 \\
\hline & 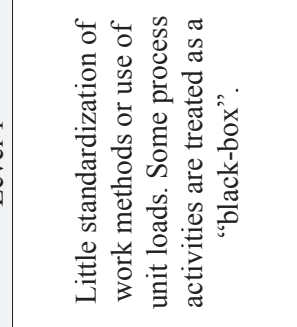 & 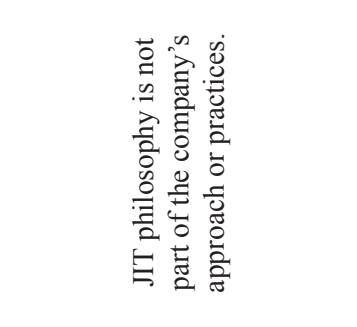 & 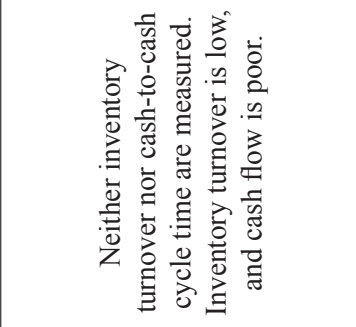 \\
\hline & 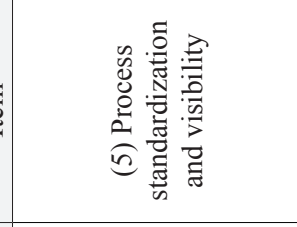 & 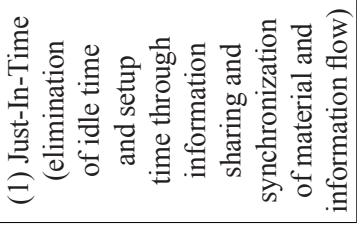 & 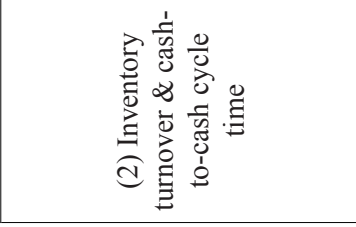 \\
\hline & & & \\
\hline
\end{tabular}




\begin{tabular}{|c|c|c|c|}
\hline 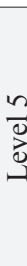 & 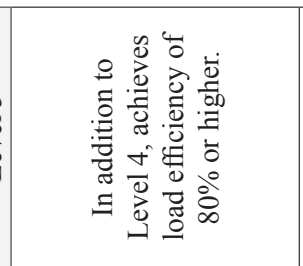 & 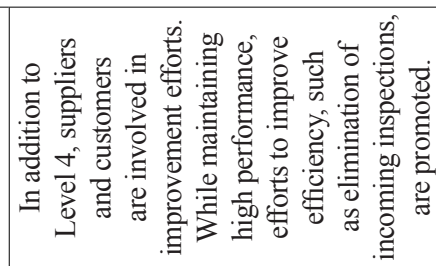 & 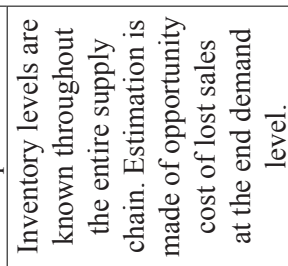 \\
\hline$\frac{7}{9}$ & 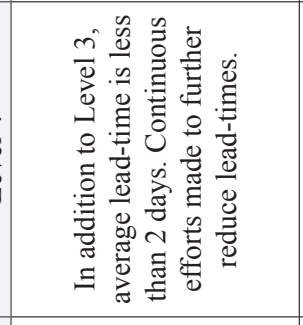 & 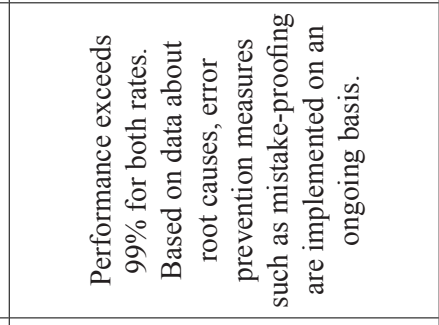 & 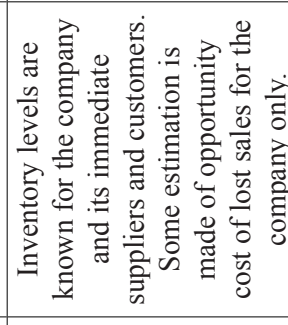 \\
\hline & 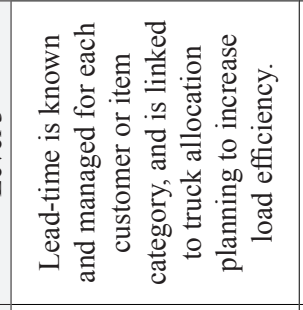 & 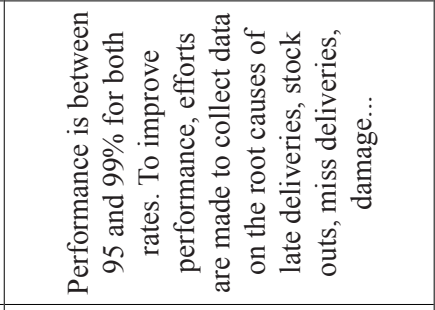 & 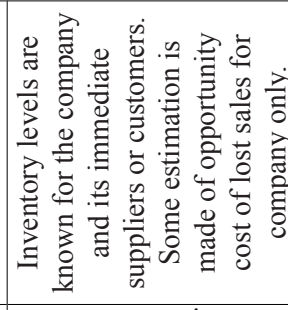 \\
\hline & 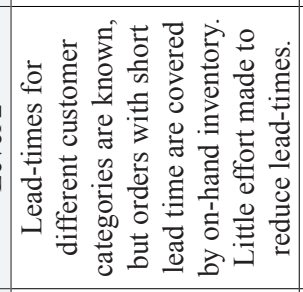 & 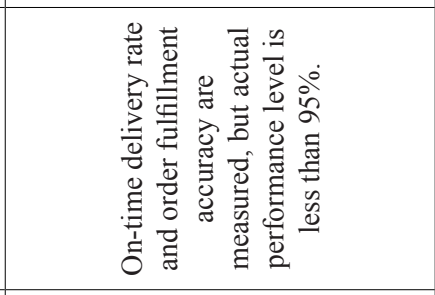 & 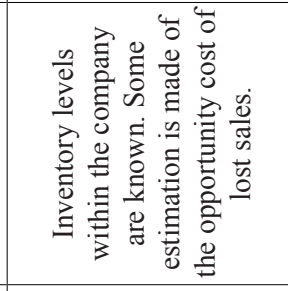 \\
\hline $\bar{a}$ & 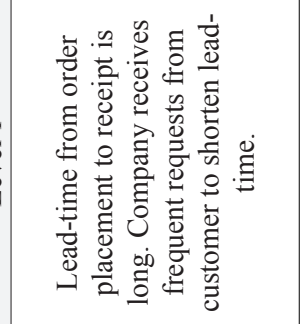 & 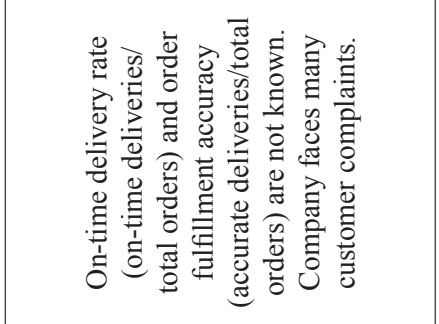 & 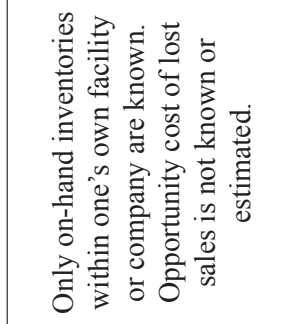 \\
\hline 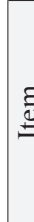 & 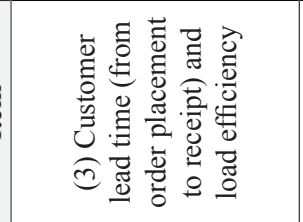 & 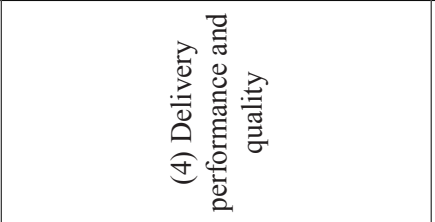 & 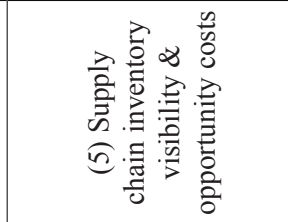 \\
\hline & & 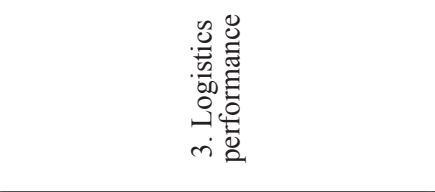 & \\
\hline
\end{tabular}




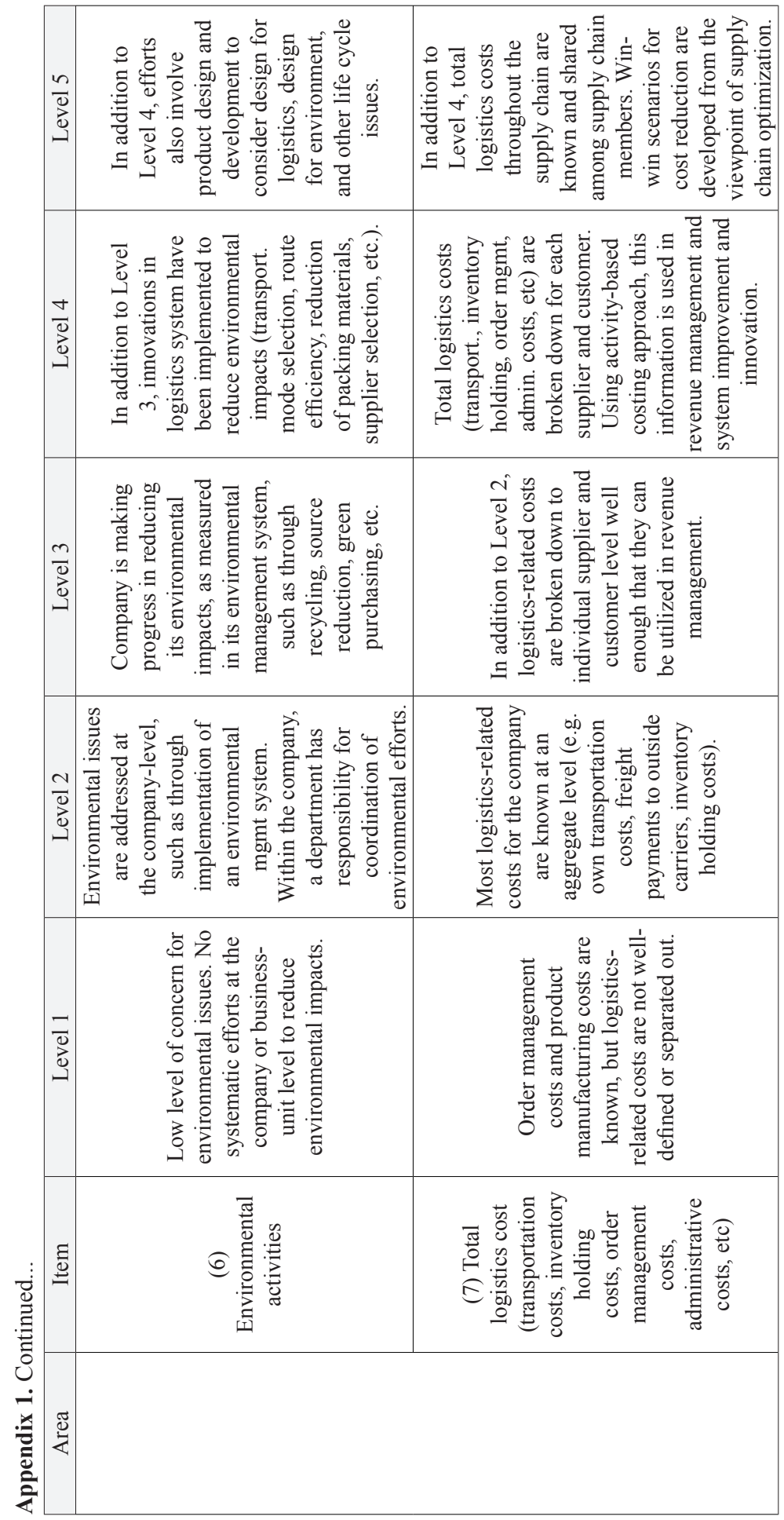




\begin{tabular}{|c|c|c|c|}
\hline & 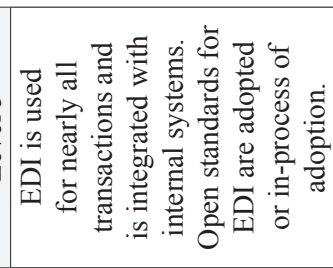 & 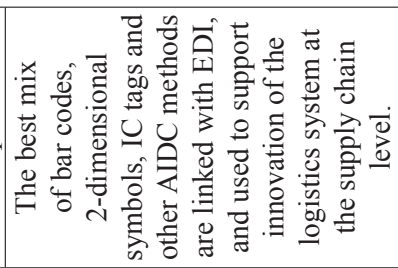 & 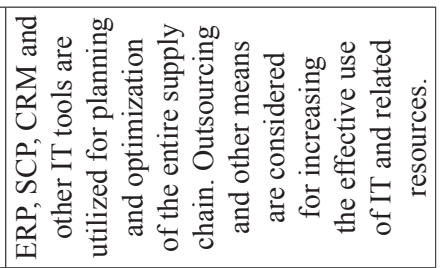 \\
\hline 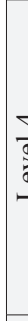 & 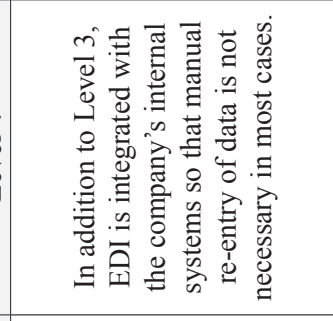 & 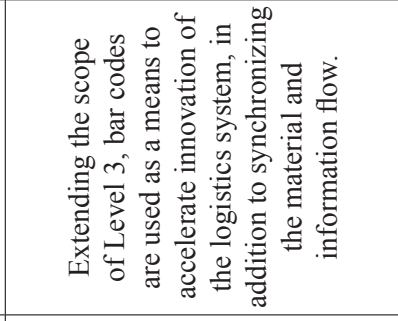 & 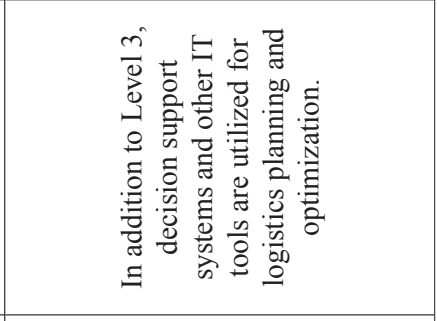 \\
\hline - & 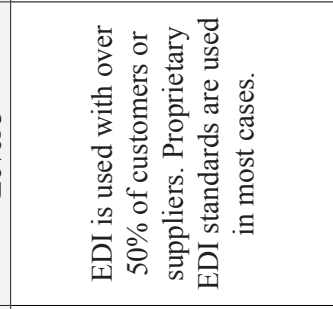 & 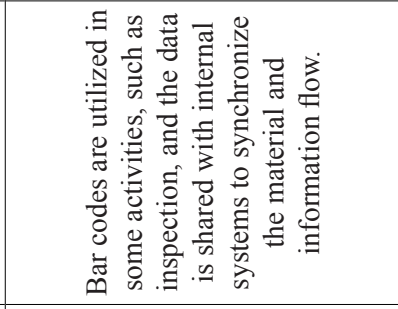 & 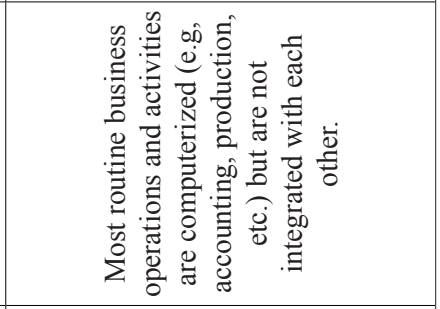 \\
\hline & 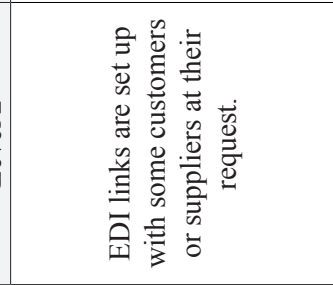 & 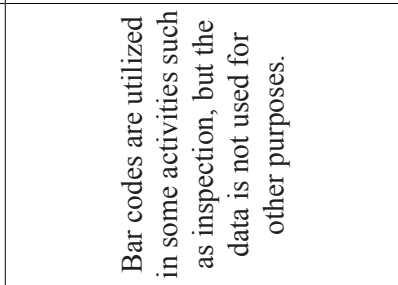 & 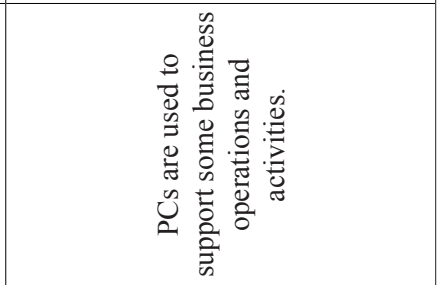 \\
\hline & 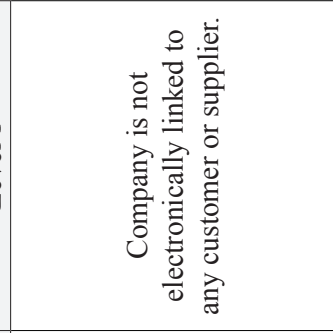 & 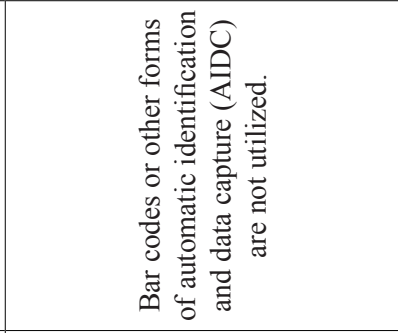 & 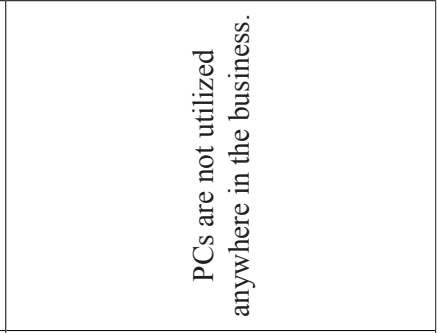 \\
\hline & 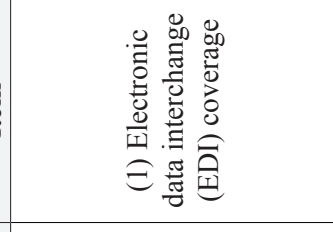 & 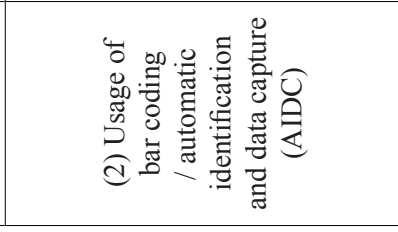 & 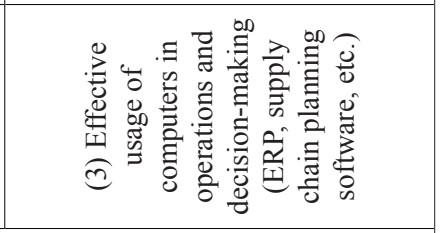 \\
\hline & 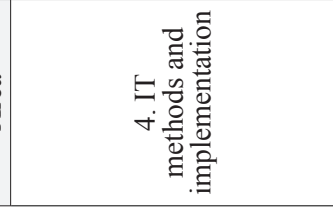 & & \\
\hline
\end{tabular}




\begin{tabular}{|c|c|c|}
\hline & 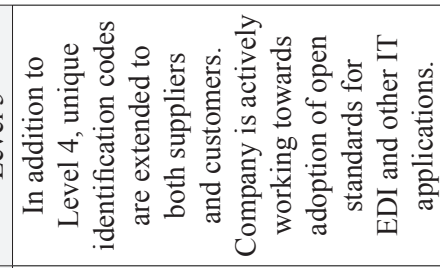 & 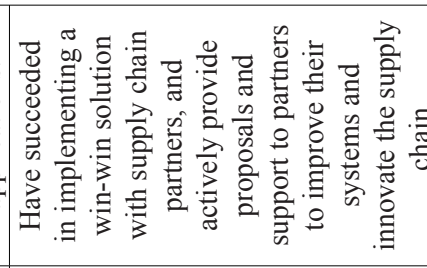 \\
\hline & 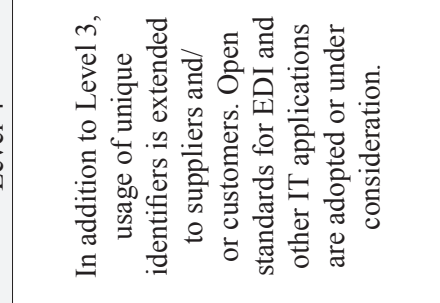 & 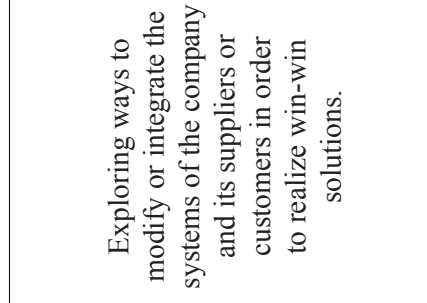 \\
\hline & 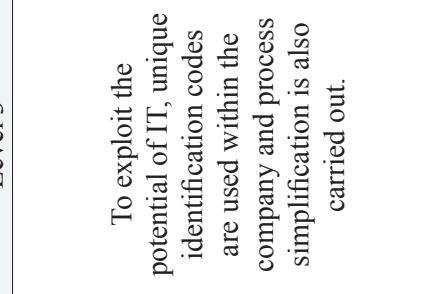 & 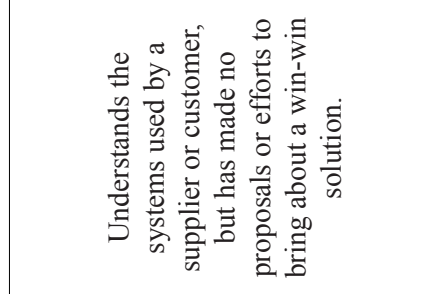 \\
\hline & 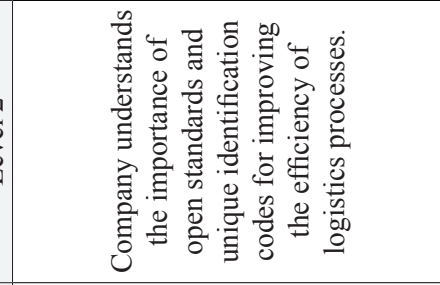 & 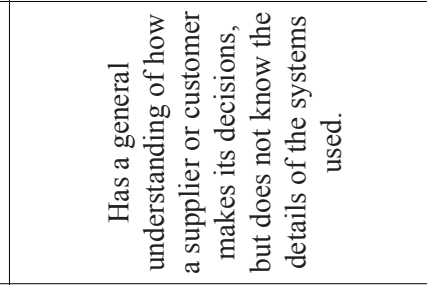 \\
\hline & 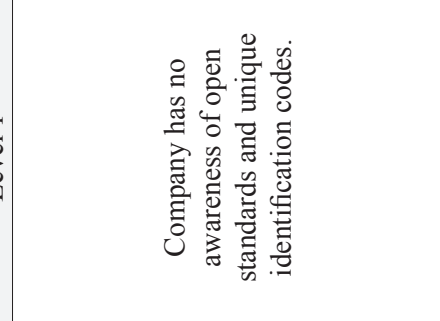 & 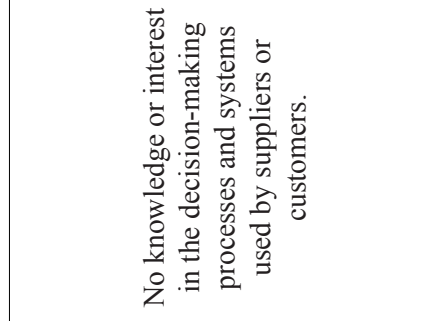 \\
\hline & 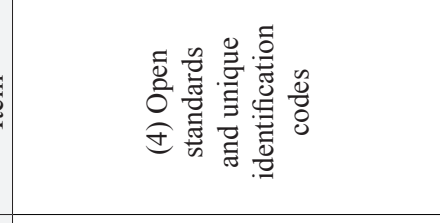 & 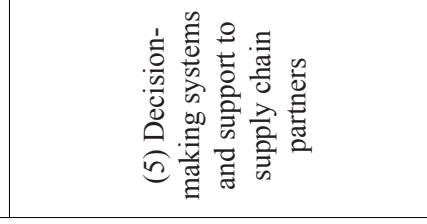 \\
\hline & & \\
\hline
\end{tabular}

